Article

\title{
Knowledge Leakages and Ways to Reduce Them in Small and Medium-Sized Enterprises (SMEs)
}

\section{Susanne Durst ${ }^{1, *}$ and Helio Aisenberg Ferenhof ${ }^{2}$}

1 School of Business, University of Skövde, Högskolevägen, 54128 Skövde, Sweden

2 Department of Production Engineering and Systems, Federal University of Santa Catarina (UFSC), Campus Trindade, Florianópolis/SC, 88.040-900, Brazil; E-Mail: helio.ferenhof@posgrad.ufsc.br

* Author to whom correspondence should be addressed; E-Mail: susanne.durst@his.se;

Tel.: +46-500-448589.

Received: 28 June 2014; in revised form: 29 August 2014 / Accepted: 29 August 2014 /

Published: 4 September 2014

\begin{abstract}
In this paper, we look into knowledge leakages and ways to address them. It is conducted from the point of view of small and medium-sized enterprises (SMEs), as their specific attributes create unique challenges. Based on a discussion of the relevant fields, ways are presented in order to reduce the danger of knowledge leakages. In view of practitioners, the paper's findings may enable an increased awareness towards the areas where existing knowledge is at the mercy of "leakage". This can assist managers of SMEs to better cope with risks related to knowledge leakage and, therefore, better exploit the (limited) knowledge base available.
\end{abstract}

Keywords: knowledge leakage; knowledge management; knowledge loss; knowledge risk management; SMEs; small and medium-sized enterprises; smaller firms

\section{Introduction}

Assuming that knowledge is the key resource needed to remain competitive [1], firms, regardless of size, need to find ways to properly manage their knowledge in order to address this challenge. Thereby, the firms' knowledge management (KM) needs to take a holistic approach, meaning that their KM activities should not be limited to knowledge creation and knowledge dissemination but should involve activities related to knowledge retention as well. According to Martins and Meyer [2] (p. 80), knowledge retention can be defined as "maintaining, not losing, knowledge that exists in the minds of 
people (tacit, not easily documented) and knowing (experiential action manifesting in behavior) that is vital to the organization's overall functioning". In fact, knowledge retention combined with knowledge transfer can help organizations to reduce the danger of knowledge leakage or loss [3]. If organizations fail to address this challenge, their organizational productivity is particularly at risk in situations when critical staff is leaving which typically does not allow for an immediate replacement [4], to name just one example. Or even worse the organizations lose their capacity to act [5].

Coping with this challenge should be of particular importance to small and medium-sized enterprises (SMEs) as they dispose of fewer knowledge resources compared to their larger counterparties. Accordingly, erroneous decisions with regard to knowledge or its management will have more serious complications in SMEs than they will have in larger businesses [6]. Even though a mass of theoretical and empirical work has been conducted in the field of KM in general, this is not the situation regarding KM in SMEs. Indeed, there is a lack of studies regarding knowledge retention in particular [7]. This can be assessed as not satisfactory, as SMEs are said to be more vulnerable to problems of knowledge retention than large companies are [8]. Thus, knowledge leakage should constitute an even more serious challenge to SMEs.

Keeping this in mind, the aim of this conceptual paper is to study knowledge leakages in organizations. More precisely, the emphasis lies on knowledge leakages and ways to reduce them. In an attempt to reach this aim, extant KM theory is drawn on to advance a framework that highlights possible solutions. The discussion is conducted from the viewpoint of SMEs. Given the limited body of knowledge regarding the topic, the proposed framework may be useful for managers of SMEs and other actors interested in SMEs. The focus is on highlighting different areas of knowledge leakage and on proposing ways of addressing these areas. Having an understanding of different areas and possible options available is considered as a fundamental basis for any following knowledge retention activities.

The paper is structured as follows. The following sections discuss the theoretical background of this paper. This comprises a discussion of the relevant issues related to SMEs and knowledge leakage. After that the, findings are summarized in a conceptual framework. The paper concludes with implications for theory and practice, as well as suggestions for future research avenues.

\section{Theoretical Background}

\subsection{Small and Medium-Sized Enterprises}

In this paper, the SME definition as proposed by the European Commission [9] is followed. According to the commission SMEs can be classified as micro, small, or medium-sized depending on the number of employees, annual turnover, or balance sheet totals. Referring to the number of employees, a company with fewer than ten employees it is considered to be a micro firm, between ten and 49 employees a firm is considered to be a small firm, and, between 50 and 249 employees, one speaks of a medium-sized firm. Considering this broad range and sector heterogeneity [10], comparisons between the different sub-types of SMEs are rather difficult.

In addition to quantitative definitions, qualitative characteristics are utilized to define SMEs. According to Behringer [11], SMEs can be described using the following features: they are independent (legally and economically); they are not publicly traded; and there is an overlapping of 
ownership and management. Many SMEs have limited resources (i.e., financial capital, human capital, and so on) [12]. Therefore, these resources have to be used with care, as erroneous decisions will have more serious complications than they will have in large firms [6]. In addition, in many SMEs, the dominant owner or the family, respectively, take on a central position [12]. This centrality also suggests that, particularly, these persons are responsible for the introduction of new measures, for example, related to knowledge retention, in order to support the firm's development and, hence, its survival. Moreover, specifically in smaller SMEs, day-to-day operations require high attention [13], resulting very often in the situation that time is missing to identify and implement new approaches to address present or future business challenges.

Research related to knowledge management in SMEs as well as family firms is scant $[7,14,15]$. In the context of SMEs, Cabrera-Suárez, De Saá-Pérez, and García-Almeida [16], arguing from a resource and knowledge-based view, highlighted the meaning of knowledge transfer in view of company succession. The authors particularly emphasized the relevance of the founder's tacit knowledge for the firm and, thus, the importance of transfer of it during the succession process. In another study, Chirico [14] underlined the aspect of how knowledge can be accrued in family firms. Therefore, the study showed the significance of keen family relationships as an important source for knowledge accumulation. The studies available on knowledge management practice in SMEs imply that these firms are less advanced when dealing with the topic [17]. Furthermore, they are "having a more mechanistic approach to knowledge construction and relying less on social interaction" compared to large businesses [18] (p. 240). Apparently, although (internal) knowledge is assessed as high among this type of firms, only modest and ad hoc measures are introduced to systematically deal with existing knowledge [19]. This might be explained by a pragmatic approach to competition and survival as is found in many SMEs [20]. However, against the background of the present paper this situation can be described as dangerous since many SMEs are specialized in niche-markets [21] which require specific knowledge. Additionally, not having access to appropriate and up-to-date knowledge makes it more challenging to cope with present and future business challenges [20]. However, at the same time, missing or inappropriate KM practices will increase the danger of knowledge leakage and loss [20].

\subsection{Knowledge Leakage}

Extant literature highlights two different meanings for knowledge leakage: (1) knowledge and capability shortage. This refers mainly to turnover, i.e., individuals retire, move to another organization, or leave an organization due to other reasons. Regardless of the specific form of turnover, those individuals take their tacit knowledge and relational capital with them and it is often the case that there is no one in the organization experienced and skilled enough to replace them [19,22-24]; (2) knowledge exposure. This reveals itself when organizations enter into strategic alliances, such as joint ventures, contract consultants, outsource parts of their business functions, or in situation where parts of the core knowledge are transferred to others, e.g., in contractual agreements, such as franchising or licensing [3,21,25-28]. Jiang et al. [29] (p. 984), relating to the latter, define knowledge leakage as "the extent to which the focal firm's private knowledge is intentionally appropriated by or unintentionally transferred to partners". Lau et al. [30] (p. 966) associate knowledge leakage with technology and define it as "the risk of loss of proprietary technology owned by" a company. 
Even though $\mathrm{KM}$ in general and some specific KM practices (such as knowledge transfer or knowledge acquisition) represent topics that have, intensively, been studied, this is not the case with knowledge leakage [31]. Indeed, a review of extant literature about knowledge leakage revealed that our body of knowledge is rather limited. The following provides some insights into the current stage of research.

To reduce leakages as result of retirement, Aiman-Smith et al. [22] highlight the benefits of phased retirement. The authors also recommend making effective use of the leaving organization members before and after retirement. For example, this could occur through the implementation of mentoring programs and after by hiring the retirees as consultants to further support the organization. Additionally, Aiman-Smith et al. [22] propose other practices for mitigating knowledge leakage in organizations: (1) Making use of global skills resource management; (2) Employee rotational programs; (3) Sharing case studies of lessons learned; (4) Using communities of practice; (5) Storytelling; (6) Training and educating programs (such as shadowing); (7) Strengthening recruiting relationships; and (8) Creating a knowledge manager position or an entire knowledge management department. A structural process of knowledge transfer based on loyalty and trust is highlighted by Boersma [23] as a promising way of mitigating knowledge leakage. This is in line with Andersén [3] (p. 445) who argues that "a culture of loyalty is likely to reduce leakage of knowledge". Coyte et al. [32] propose the use of intentional informal controls through small teamwork structures. With this approach, knowledge can be managed by creating a team environment where duties and functions are shared between people enabling sufficient overlap to cover absences and departures. In order to cope with leakage provoked by turnover and retirement, Iske and Boersma [24] propose the use of Questions and Answers (Q\&A) systems. According to the authors, these systems can offer huge opportunities for creating value by developing, sharing and applying knowledge. In a rare study of knowledge leakage conducted in SMEs, Durst and Wilhelm [19] provided insights into how a case company addressed the danger of knowledge attrition initiated by turnover or long-term absence. The study clarifies that regarding knowledge attrition it is more about initiating actions than rather about creating awareness, that is, Pfeffer and Sutton' [33] "knowing-doing gap" needs to be challenged.

As stated above and not surprisingly, knowledge leakage is often associated with collaborations and alliances. Depending on the operationalization of these activities knowledge leakage can occur. For example, an in inclusion of partners into in new idea generation can result not only in a number of actual new ideas but in involuntary knowledge leakage to the partners involved as well [17]. Also contractual collaborative arrangements such as licensing and franchising represent areas of knowledge leakage [34]. Outsourcing is considered another form of collaborative arrangement that increases the danger of knowledge leakage [35]. The latter may represent itself in terms of technical and problem solving skills and productivity [36]. As a consequence, firms try to find ways to reduce unintended knowledge outflows [28]. In this context, the study by Parker [31] can be named. He studied the role of governance on knowledge acquisition and loss by new technology-based firms engaged in inter-firm collaborative new product development projects. His findings showed that while knowledge acquisition is fostered by relational governance mechanisms, knowledge loss/leakage is better addressed with contractual governance mechanisms. Parker's study clarifies that one governance approach is not sufficient to address different KM practices. In addition, it makes KM activities in SMEs even more challenging. Oxley and Sampson [28] examined how the limitation of the scope of 
the alliance can help firms in addressing knowledge leakage. Their findings suggest that reducing the scope of the alliance may be advisable in competitive environments and therefore could act as an alternative to protective governance mechanisms. Oxley and Wada [21] demonstrated that an equity joint venture structure increases knowledge sharing between the partners partly due to the fact that unintended knowledge leakage is reduced. The risk of knowledge leakage also increases with the partners' possession of adequate absorptive capacity, i.e., "the ability to recognize the value of new information, assimilate it, and apply it to commercial ends" [37] (p. 128). Closely related to the absorptive capacity is the issue of feasibility, i.e., a partner's capacity to actually implement what they have gleaned from the other partner [28]. Research also suggests that the number of partners involved in an alliance increase the risk of knowledge leakage, as the more partners are involved the more difficult to monitor [28]. As already addressed before, not only the number of partners may increase the danger of knowledge leakage, but also the type of partners. Partners who compete directly will have a greater exposure to knowledge leakage than partners who compete indirectly or not at all [21,28].

The review presented above makes clear that if knowledge leakage is examined, if any, it is predominately discussed in a large or multinational firm context. The study of knowledge leakage is underdeveloped, yet, under no circumstances, should one try to transfer approaches developed for large organizations, one-to-one, to SMEs. This will not be promising, given the heterogeneity among and specific attributes of SMEs.

\section{Framework for Addressing Knowledge Leakages}

The assessment of the reviewed literature presented above led to the development of an initial framework that not only highlights the areas of knowledge leakage but proposes ways to reduce them as well (Figure 1).

The framework highlights six areas of knowledge leakage. The key drivers of knowledge leakage (suppliers, customers, competitors, non-competitive organizations, human resources) proposed by Chan et al. [38] were considered as a sound basis for the development of our framework as their taxonomy emphasizes the special role internal and external people play in the context of knowledge leakage. More precisely the authors' emphasis on interactions between different stakeholders are of interest in the context of SMEs as they tend to be good networkers [39], which in turn increases the danger of knowledge leakage. This situation illustrates the link between knowledge leakage and stakeholder theory [40], even though Chan et al. do not make any reference to it. Chan et al.' [38] drivers, which were the outcomes of a literature review and a series of exploratory interviews with senior managers and who represented a different sectors and categories of firm were expanded by the area of organizational structure because, here too, knowledge leakage can arise. In the present paper, organizational structure refers to the organization's structures and processes, which are necessary to react properly to changing market needs and/or business environments and thus maintain and enhance the organization's capacity to act. Additionally, the area "non-competitive organizations" has been changed to "other stakeholders" in order to clarify that knowledge leakage can also arise in situations where the organization exchange with presumed non-business persons/organizations, e.g., politicians or the general public. 
Figure 1. Framework for addressing knowledge leakages in small and medium-sized enterprises.

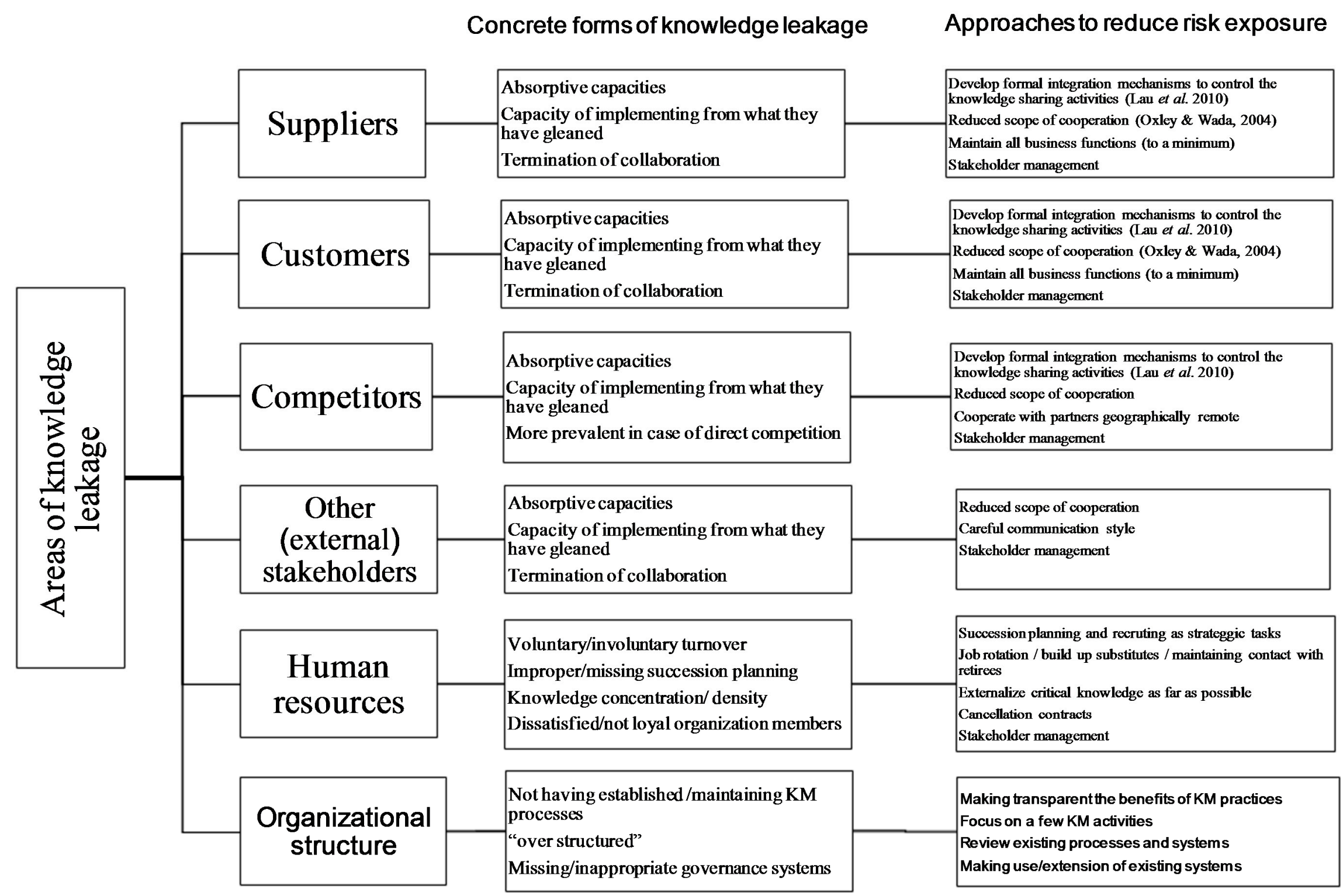


Next the framework lists for each area concrete forms of how knowledge leakage may occur. These forms were derived from the literature review presented above. This is then followed by proposals on how SMEs could address the different knowledge leakage incidents. As the proposals indicate the authors of this paper tried to incorporate the specific characteristics of SMEs in order to reflect small firms' reality.

Recalling the theoretical discussion provided above, it is not surprising that the danger of knowledge leakage with external partners is the highest when they actually dispose of the right absorptive capacities and the possibility to implement what they have figured out from the organization concerned. Consequently, this danger has to be seen in relative terms and, for instance, a mere threat of forward or backward integration is insufficient. On the other hand, the termination of cooperation could be an alarm signal, as it may indicate more than just the completion of a joint project but also that the partner had achieved what they set out to do, i.e., the acquisition of a specific skill or capacity. Additionally, depending on the type of collaboration, it might also be the situation that the small firm has lost knowledge about certain business functions because of too high a level of specialization.

As possible ways of coping with knowledge leakage are concerned, reducing the scope of cooperation as highlighted by Oxley and Sampson [28] meets SMEs practices and capabilities, as they by nature are more likely to execute a manageable number of business activities. Regarding external stakeholders it is important to stress that areas of knowledge leakage can be found everywhere, i.e., in private and professional spheres, which means in turn that one must be careful not to unintentionally divulge material business facts. With respect to collaborations in general, SMEs need to make sure that they do not lose their capacity to act because of being too specialized as, otherwise, the danger is high that they will have lost the specific skills and capacities required to perform typical business functions once the collaboration has finished (scheduled or non-scheduled). Additionally, as knowledge leakage is mainly the result of interactions between various internal and external stakeholders, SMEs should actively pursue stakeholder management as it provides helpful approaches to address the danger of knowledge leakage [41]. For example, stakeholder mapping would help SMEs to identify those primary stakeholders that pose the most serious threat concerning knowledge leakage [42].

\section{Conclusions}

Understanding the danger of knowledge leakage and areas in which they can present themselves is essential and can contribute to a better knowledge management in organizations. Thus, it represents an important progress for KM theory. Previous research has underestimated this. Taking an SME viewpoint, the framework presented here takes up this idea and develops a more comprehensive understanding of the critical meaning of managing knowledge leakage. The framework has been developed based on a synthesis of existing literature and represents a further development of Chan et al.' [38] taxonomy of knowledge leakage. The framework presented in this paper provides not only concrete areas of knowledge leakage but it suggests ways to reduce the danger of knowledge leakage as well. Furthermore, it takes a clear SME perspective. This clarifies the framework's merits. Given the resource constraints many SMEs are facing, this category of firms could benefit considerably from such a comprehensive approach. 
Knowledge leakage is difficult to avoid in many situations, e.g., if an innovative or an integrated product is developed [30], still, as outlined in this paper, there are other situations where this challenge can and should be addressed as otherwise the organization's competitiveness might be at risk. The paper has also indicated that the handling of knowledge leakage is not a matter of size. SMEs as well have different approaches available to address knowledge leakage.

Consequently, the idea and the framework presented in this article may be useful for managers of SMEs and other actors interested in them. The framework appears to be a valuable tool for understanding possible areas of knowledge leakage, concrete forms of these knowledge leakages and ways of addressing them. This understanding is viewed as of high importance as it may guide managers of SMEs and other actors (e.g., advisors) in their courses of action. Accordingly, the framework may serve as visual aid for these groups. Managers of SMEs may create an increased awareness towards the issue of knowledge leakage and more important may initiate concrete actions to cope with this challenge in their organizations. This will assist them to better handle the risks related to knowledge leakage and, as a consequence, to better manage the knowledge base available. The list of areas of knowledge leakage presented may also raise awareness towards the variety of possible risks associated with knowledge leakage. This could reduce the potential danger that only obvious risks are being considered, e.g., those related to human resources. Thus, the framework may help to develop a sensitization of managers of SMEs for the variety of areas related to knowledge leakage and their probable implications for the organization's capacity to act. In view of advisors, the framework may facilitate an expansion of their field of assistance.

The topic seems to be a promising field for intensive research and offers a variety of future research avenues. For example, a closer analysis of the SMEs' handling of their knowledge retention activities would provide a useful basis for the further development of knowledge (risk) management approaches. A better understanding of SME business operations would help to develop SME solutions that keep the danger of business disruptions triggered by knowledge leakage at a minimum. In addition, the areas of knowledge leakage and the ways proposed to reduce the risk exposure should be exposed to a reality check. This means that they should be tested for relevance and suitability in different types of SMEs. For example, the items could be tested within a sample of small firms and a sample of medium-sized firms as well as in different sectors. Future research may also focus on the weighing of the areas of knowledge leakage proposed.

\section{Acknowledgment}

Helio Aisenberg Ferenhof gratefully acknowledges support from the CAPES (Coordenação de Aperfeiçoamento de Pessoal de Nível Superior), Proc. n BEX 5151/14-7.

\section{Author Contributions}

Susanne Durst has developed the idea of the paper. She has developed and written the manuscript. Helio Aisenberg Ferenhof conducted the literature review on knowledge leakage and has supported in writing parts of the section on knowledge leakage. Both authors have read and approved the final manuscript. 


\section{Conflicts of Interest}

The authors declare no conflict of interest.

\section{References}

1. Spender, J.C. Making knowledge the basis of a dynamic theory of the firm. Strateg. Manag. J. 1996, 17, 45-62.

2. Martins, E.C.; Meyer, H.W.J. Organizational and behavioral factors that influence knowledge retention. J. Knowl. Manag. 2012, 16, 77-96.

3. Andersén, J. Protective capacity and absorptive capacity: Managing the balance between retention and creation of knowledge-based resources. Learn. Org. 2012, 19, 440-452.

4. Hall, R. The strategic analysis of intangible resources. Strateg. Manag. J. 1992, 13, 135-144.

5. Delong, D.W. Lost knowledge. Confronting the Threat of an Aging Workforce; Oxford University Press: Oxford, UK, 2004.

6. Amelingmeyer, J.; Amelingmeyer, G. Wissensmanagement beim Führungswechsel in KMU. In Wissens- und Informationsmanagement in kleinen und mittleren Unternehmen; Meyer, J.-A., Ed.; Josef Eul Verlag: Lohmar, Germany, 2005; pp. 479-488. (In German)

7. Durst, S.; Edvardsson, I.R. Knowledge management in SMEs: A literature review. J. Knowl. Manag. 2012, 16, 879-903.

8. Nunes, M.B.; Annansingh, F.; Eaglestone, B.; Wakefield, R. Knowledge management issues in knowledge-intensive SMEs. J. Doc. 2006, 62, 101-119.

9. European Union Commission. Commission recommendation of 6 May 2003 concerning the definition of micro, small and medium-sized enterprises. Official Journal of the European Union 2003, 46, 36-41. Available on http://eur-lex.europa.eu/legal-content/EN/TXT/?uri=uriserv: OJ.L_.2003.124.01.0036.01.ENG (accessed on 2 September 2014).

10. Curran, J.; Blackburn, R.A. Researching the Small Enterprise; Sage: London, UK, 2001.

11. Behringer, S. Unternehmensbewertung der Mittel- und Kleinbetriebe; Erich Schmidt Verlag: Berlin, Germany, 2002. (In German)

12. Carney, M. Corporate governance and competitive advantage in family-controlled firms. Entrep. Theory Pract. 2005, 29, 249-265.

13. Hofer, C.; Charan, R. The transition to professional management: mission impossible? Am. J. Small Bus. 1984, 9, 1-11.

14. Chirico, F. Knowledge accumulation in family firms. Int. Small Bus. J. 2008, 26, 433-62.

15. Hutchinson, V.; Quintas, P. Do SMEs do knowledge management? Or simply manage what they know? Int. Small Bus. J. 2008, 26, 131-54.

16. Cabrera-Suárez, K.; De Saá-Pérez, P.; García-Almeida, D. The Succession Process from a Resource- and Knowledge-Based View of the Family Firm. Fam. Bus. Rev. 2001, XIV, 37-47.

17. Wong, K.Y.; Aspinwall, E. An empirical study of the important factors for knowledge-management adoption in the SME sector. J. Knowl. Manag. 2005, 9, 64-82.

18. McAdam, R.; Reid, R. SME and large organisation perceptions of knowledge management: Comparisons and contrasts. J. Knowl. Manag. 2001, 5, 231-241. 
19. Durst, S.; Wilhelm, S. Knowledge Management and Succession Planning in SMEs. J. Knowl. Manag. 2012, 16, 637-649.

20. O'Gorman, C. Strategy and the small business. In Enterprise and Small Business, 2nd ed.; Carter, S., Jones-Evans, D., Eds.; Pearson: Harlow, UK, 2006; pp. 406-422.

21. Oxley, J.; Wada, T. Alliance structure and the scope of knowledge transfer: Evidence from US-Japan agreements. Manag. Sci. 2009, 55, 635-649.

22. Aiman-Smith, L.; Bergey, P.; Cantwell, A.R.; Doran, M. The coming knowledge and capability shortage. Res.-Technol. Manag. 2006, 49, 15-23.

23. Boersma, A. KM in China: Western heads in Eastern hands? VINE 2010, 40, 254-261.

24. Iske, P.; Boersma, W. Connected brains: Question and answer systems for knowledge sharing: Concepts, implementation and return on investment. J. Knowl. Manag. 2005, 9, 126-145.

25. Ferdinand, J.; Simm, D. Re-theorizing external learning: insights from economic and industrial espionage. Manag. Learn. 2007, 38, 297-317.

26. Henard, D.H.; McFadyen, M. R\&D knowledge is power. Res.-Technol. Manag. 2006, 49, 41-47.

27. Hoecht, A.; Trott, P. Outsourcing, information leakage and the risk of losing technology-based competencies. Eur. Bus. Rev. 2006, 18, 395-412.

28. Oxley, J.E.; Sampson, R.C. The scope and governance of international R\&D alliances. Strateg. Manag. J. 2004, 25, 723-749.

29. Jiang, X.; Li, M.; Gao, S.; Bao, Y.; Jiang, F. Managing knowledge leakage in strategic alliances: The effects of trust and formal contracts. Ind. Mark. Manag. 2013, 42, 983-991.

30. Lau, A.K.; Yam, R.C.; Tang, E.P.; Sun, H. Factors influencing the relationship between product modularity and supply chain integration. Int. J. Oper. Prod. Manag. 2010, 30, 951-977.

31. Parker, H. Knowledge acquisition and leakage in inter-firm relationships involving new technology-based firms. Manag. Decis. 2012, 50, 1618-1633.

32. Coyte, R.; Ricceri, F.; Guthrie, J. The management of knowledge resources in SMEs: an Australian case study. J. Knowl. Manag. 2012, 16, 789-807.

33. Pfeffer, J.; Sutton, R.I. The Knowing-Doing Gap. How Smart Companies Turn Knowledge into Action, Harvard Business School Press: Boston, MA, USA, 2000.

34. Simone, C.; Proietti, L. Wholly proprietary versus wholly open knowledge strategies: some empirical evidences from Italian biotech firms. J. Manag. Gov. 2012, 16, 425-447.

35. Mazzanti, M.; Montresor, S.; Pini, P. Outsourcing and innovation: evidence for a local production system of Emilia-Romagna. Innov. Manag. Policy Pract. 2007, 10, 324-342.

36. Daghfous, A.: Belkhodja, O.; Angell, L.C. Understanding and managing knowledge loss. J. Knowl. Manag. 2013, 17, 639-660.

37. Cohen, W.M.; Levinthal, D.A. Absorptive capacity: A new perspective on learning and innovation. Adm. Sci. Q. 1990, 35, 128-152.

38. Chan, P.; Grantham, A.; Kaplinsky, R.; Mynors, D.; Mohamed, S.; Walsh, K.; Coles, R. Taxonomy of knowledge leakage: Some early developments. In Proceedings of the 22nd Annual ARCOM Conference, Birmingham, UK, 4-6 September 2006; Boyd, D., Ed.; Association of Researchers in Construction Management: UK, 2006; ISBN 09555239001.

39. Gilmore, A.; Carson, D.; Grant, K. SME marketing in practice. Mark. Intell. Plann. 2001, 19, $6-11$. 
40. Freeman, R.E. Strategic management: A stakeholder approach; Cambridge University Press; Cambridge, UK, 2010.

41. Freeman, R.E.; Harrison, J.S.; Wicks, A.C. Managing for stakeholders: Survival, reputation, and success; Yale University Press: New Haven, CT, USA, 2007.

42. Mitchell, R.K.; Agle, B.R.; Wood, D.J. Toward a Theory of Stakeholder Identification and Salience: Defining the Principle of Who and What really Counts. Acad. Manag. Rev. 1997, 22, 853-886.

(C) 2014 by the authors; licensee MDPI, Basel, Switzerland. This article is an open access article distributed under the terms and conditions of the Creative Commons Attribution license (http://creativecommons.org/licenses/by/3.0/). 